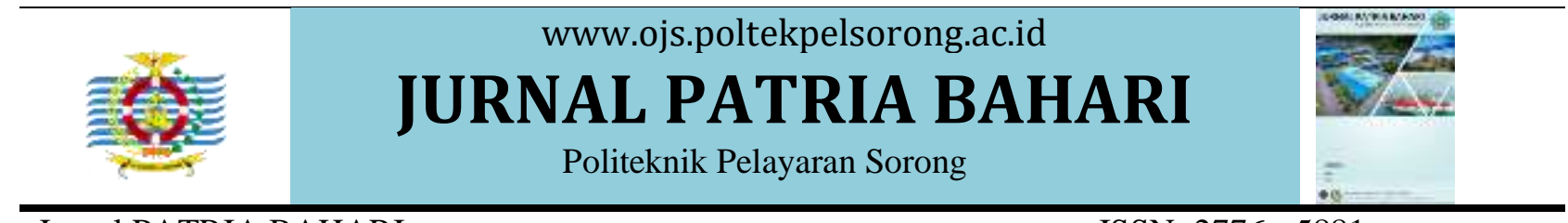 \\ Jurnal PATRIA BAHARI \\ Vol. 1, No. 2, November 2021 \\ pISSN: $2776-5881$ \\ Hal 53-57 \\ eISSN: 2798 - 0510
}

\section{PROTOTYPE DETEKSI OBJEK MENGGUNAKAN RASPBERRY PI MELALUI MODUL SENSOR ULTRASONIK HC-SR04}

\author{
Oleh \\ Raditya Faisal Waliulu', Arizal Hendriawan ${ }^{2}$, Supardi $^{3}$, Agus Pramono ${ }^{4}$ \\ Politeknik Saintpaul Sorong ${ }^{1}$, Politeknik Pelayaran Sorong ${ }^{234}$
}

\begin{abstract}
ABSTRAK
Pendekatan deteksi objek yang dilakukan oleh radar pada perkapalan sangat intuitif dan sensitif terhadap benda yang berada dalam wilayah terjangkau sensor aktif. Menjadi suatu hal yang sangat bermanfaat, crew kapal memantau 24 Jam / 7 hari perjalanan menuju destinasi dermaga berikutnya. Sensor deteksi sangat peka terhadap wilayah yang terjangkau akan memberikan peringatan berupa sirene jika didepan terdapat halang rintang. Untuk segera menghindari atau memperlambat perjalanan kapal. Penulis membuat peneliti sebagai simulasi implementasi deteksi kapal dibuat menggunakan raspberry sebagai single board computer atau papan tunggal komputer sebagai otak sistem bekerja. Prototype ini menggunakan sensor ultrasonik HC-SR04 yang digerakan dengan 1 motor servo, dipilih sensor ultrasonic HC-SR04 tersebut karena memiliki spesifikasi yang memadai. Hasil dari pengukuran objek ditampilkan dengan aplikasi pemograman python. Dari hasil pengujian alat yaitu mampu mendeteksi objek antara $5 \mathrm{~cm}$ dari depan radar dan jarak maksimum $30 \mathrm{~cm}$ dan diperoleh tingkat kesalahan pengukuran jarak dan ketinggian sebesar $1-3 \mathrm{~cm}$ sedangkan untuk sudut $2^{0} \mathrm{~s} / \mathrm{d} 5^{0}$.
\end{abstract}

Kata kunci : sensor ultrasonik, radar lidar, kapal, deteksi, sudut

\section{PENDAHULUAN}

Radar (Radio Detecting and Ranging) merupakan salah satu alat yang diterapkan pada tiap kapal untuk navigasi serta kewaspadaan terhadap benda-benda yang jaraknya jauh dari jangkauan pandangan manusia.

Radap pada perkapalan menerapkan konsep pemantulan gelombang elektromagnetik. Tidak hanya mendeteksi benda namun juga kecepata dan arah benda tersebut bergerak, bahkan dari benda yang terdeteksi.

Kemajuan teknologi dalam menciptakan sebuah alat yang besar baiknya di proyeksikan kepada benda yang kecil. Pada permasalahan tersebut, peneliti menggunakan Raspberry Pi sebagai single board computer dan sensor HCSR04 sebagai sensor yang mendeteksi benda didepan sebagai pemantulan ultrasonik.

Penerapan prototype menggunakan raspberry, memanfaatkan panjang gelombang yang dipancarkan oleh HC-SR04 dengan panjang gelombang dalam ukuran panjang Centimeter. Gelombang ultrasonik sensitif yang dipancarkan dan dipantulkan tersebut dapat menentukan lokasi berikutnya dilakukan analisis dari gelombang yang dipantulkan. Meskipun gelombang yang diterima relatif lebih lemah namun gelombang tersebut dapat 
dideteksi dan diperkuat oleh receiver (Radar, 2018).

Hasil analisis dari benda yang terdeteksi diproyeksikan pada sebuah model GUI dengan rentang sudut deteksi mencapai 0o s/d 180o . sudut tersebut merupakan minimum dan ambang batas sudut yang dapat dilakukan oleh servo. Selanjutnya, analisis menampilkan jarak, sudut hingga ketinggian benda.

\section{METODE}

\subsection{Radar}

Radar merupakan singkatan dari Radio Detection And Ranging yang berarti suatu sistem gelombang elektromagnetik yang berguna untuk mendeteksi, mengukur jarak dan membuat map benda-benda yang berada di sekitarnya. Panjang gelombang yang dipancarkan radar bervariasi mulai dari milimeter hingga meter. Gelombang elektromagnetik yang dipancarkan dan dipantulkan dari suatu benda tertentu akan ditangkap oleh receiver. Dengan menganalisis gelombang yang dipantulkan tersebut, pemantul gelombang dapat ditentukan lokasinya dan melalui analisis lebih lanjut dari gelombang yang dipantulkan dapat juga ditentukan jenisnya. Meskipun gelombang yang diterima relatif lemah/kecil, namun gelombang tersebut dapat dideteksi dan diperkuat oleh receiver (Abdurrahman, 2015).

\subsection{Sensor Ultrasonik (HC-SR04)}

Sensor HC-SR04 ultrasonik memiliki dua buah elemen, yaitu element pembangkit gelombang ultrasonik (TX, Transmitter) dan elemen pendeteksi gelombang ultrasonk (RX, Receiver). Transmitter memancarkan 8 gelombang dengan frekwensi $40 \mathrm{KHz}$ dalam waktu $10 \mu \mathrm{S}$. Apabila gelombang yang dipancarkan transmitter mengenai objek didepan (penghalang). Maka, gelombang tersebut terpantulkan. Sehingga gelombang yang dipantulkan kembali dapat diterima oleh receiver. Terlihat seperti gambar 1

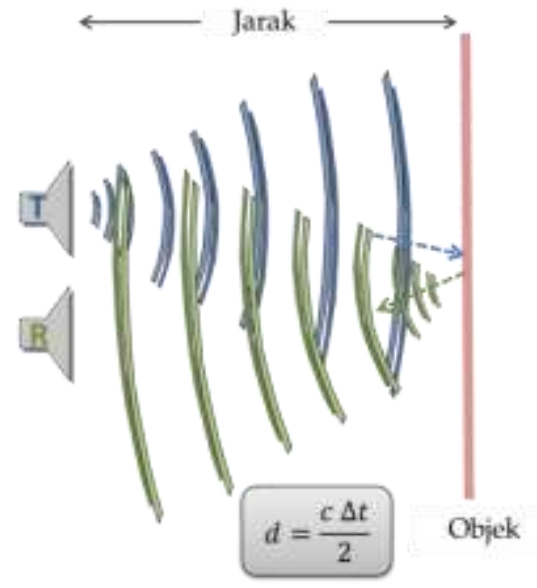

Gambar 1Cara kerja Gelombang Ultrasonik

\subsection{Komputasi tunggal (Raspberry pi)}

Raspberry Pi untuk mendeteksi suatu gerakan, sehingga sistem tersebut dapat digunakan lebih lanjut sebagai sistem keamanan. Raspberry Pi adalah komputer kecil berukuran kartu kredit. Sehingga pengguna tidak membutuhkan ruang dan tenaga yang lebih untuk membangun sistem pendeteksi gerakan (Perkasa, Widyantara, \& Susanto, 2021)

\subsection{Motor Servo}

Motor servo adalah sebuah motor DC dengan sistem umpan balik tertutup di mana posisi rotornya akan diinformasikan kembali ke rangkaian kontrol yang ada di dalam motor servo. Motor ini terdiri dari sebuah motor DC, serangkaian gear, potensiometer, dan rangkaian kontrol. Potensiometer berfungsi untuk menentukan batas sudut dari putaran servo. Sedangkan sudut dari sumbu motor servo diatur berdasarkan lebar pulsa yang dikirim melalui kaki sinyal dari kabel motor servo (Saputro, Yoto, \& Suharmanto, 2017).

\subsection{Bahasa Python}

Otomatisasi sensor terhubung dengan bahasa pemograman pyhon. Library yang dibutuhkan pada pembuatan prototype ini diantaranya pygame. Pygame sebagai library menampilkan simulasi radar pada monitor. Perlu diketahui juga saat peneliti melakukan penelitian ini menggunakan bahasa python versi 2.7 . 
(Times New Roman 11 Bold, Spasi 1)

Metode yang digunakan oleh author dalam penelitian. Metode yang dimaksud dapat menggunakan kualitatif atau kuantitatif. Selain metode yang digunakan, author dapat menambahkan ruang lingkup atau batasan penelitian atau sample yang di teliti atau digunakan dalam penelitian.

\section{HASIL DAN PEMBAHASAN}

Data Penelitian didapatkan melalui Akuisisi sensor Radar yang dipengaruhi oleh letak dan posisi objek didepan sensor. Akuisisi data menggunakan sensor ultrasonik sebagai modul HC-SR04 Komputasi tunggal Raspberry pi 3 $\mathrm{B}+$.

\subsection{Akuisisi Sensor (Jarak)}

Pada akuisisi jarak menggunakan sensor HC-SR04 lebih relevan jika jarak rintangan atau halangan sekitar $60 \mathrm{~cm}$. Hal ini di upayakan sebagai simulasi dengan skala.

\subsection{Analisis Implementasi}

Analisis data menggunakan data akuisisi sensor yang menggunakan formula matematika yang di olah dalam server database yang kemudian ditampilkan melalui layar monitor client. Rumus yang digunakan untuk mengukur jarak sensor terhadap benda:

$$
\text { Jarak }=\frac{\text { Lebar pulsa } \times 0,034}{2} \pi r^{2}
$$

Kaliberasi Jarak Terhadap Objek

$$
\sin \alpha=\frac{a}{\text { Jarak }}
$$

\subsection{Desain Skema}

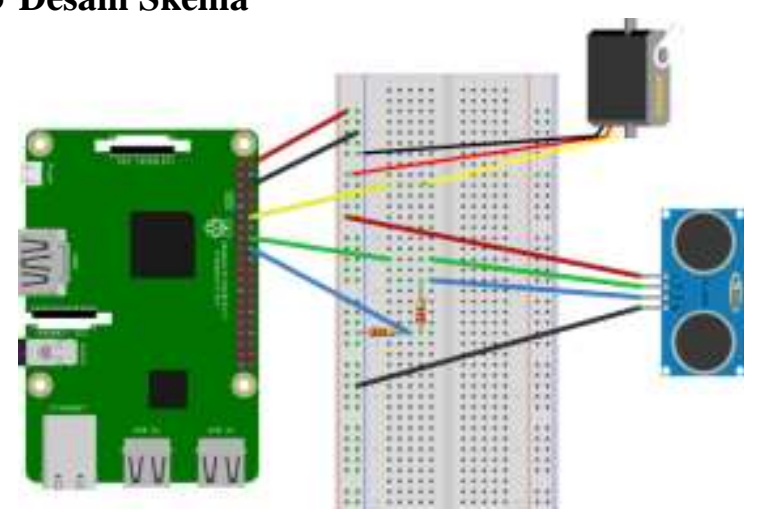

Gambar 2 Skema Sensor dan Raspberry Pi 3 B+ membahas sensitifitas kita harus memahami bagaimana sensor mengakuisisi jarak antara benda didepan dengan sensor. Posisikan radar dengan posisi sensor ultrasonik tegak 0o dengan objek lalu masukan program perhitungan ketinggian dan amati. Data hasil ketinggian didapat dari hasil inputan pergerakan motor servo secara vertical dan sensor ultrasonik. Ketinggian benda dihitung menggunakan rumus pitagoras.

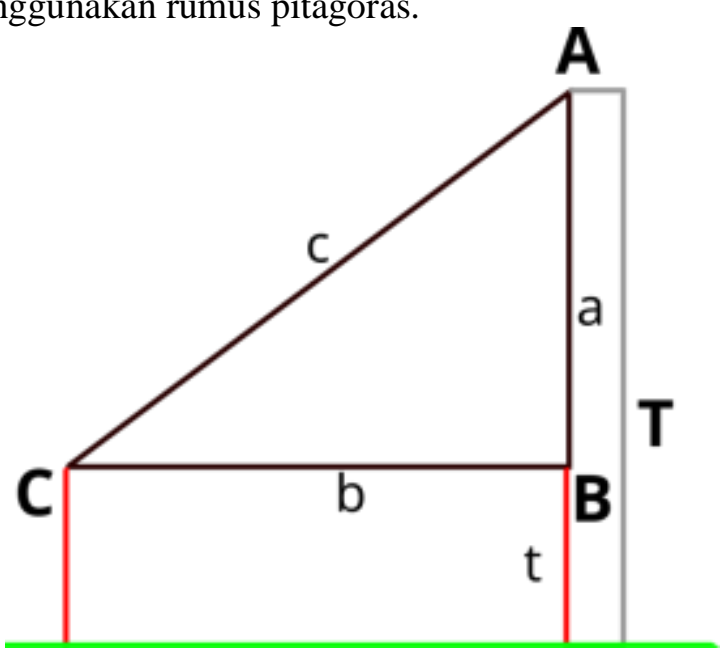

Gambar 3 Rumus Mencari Ketinggian

$b=\frac{\text { Lebar pulsa } * 0,034}{2} \pi r^{2}$

Nilai $\mathrm{C}$ muncul jika $\sin \alpha>0$

$c=\frac{\text { Lebar pulsa } * 0,034}{2} \pi r^{2}$

$\sin \alpha=\frac{a}{c}$

$$
\begin{gathered}
a=\sin \alpha * c \\
T=a+t
\end{gathered}
$$

Keterangan :

$$
\begin{aligned}
& \mathrm{A}=\text { Posisi Radar } \\
& \mathrm{B}=\text { Posisi Benda } \\
& \mathrm{C}=\text { Posisi Ketinggian } \\
& \mathrm{a}=\text { Benda } \\
& \mathrm{b}=\text { Jarak Vertikal } \\
& \mathrm{c}=\text { Jarak Horizontal }
\end{aligned}
$$$$
\alpha=\text { Sudut Pergerakkan }
$$$$
\alpha=\text { Servo motor }
$$$$
\mathrm{t}=\text { Ketinggian Radar }
$$$$
\mathrm{T}=\text { Ketinggian Seluruh }
$$

\subsection{Hasil Pengujian Radar}


Dari hasil beberapa percobaan yang telah dilakukan terdapat hasil error pada pendeteksian Radar, dari segi jarak objek, sudut pandang dan ketinggian :

\begin{tabular}{ccc|ccc}
\hline \multicolumn{5}{c}{ PERCOBAAN 1 } \\
\hline $\begin{array}{c}\text { Objek } \\
(\mathbf{c m})\end{array}$ & $\begin{array}{c}\text { Sudut } \\
\text { Pandang } \\
\left(\mathbf{(}^{\mathbf{C}}\right)\end{array}$ & $\begin{array}{c}\text { Ketinggi } \\
\text { an }(\mathbf{c m})\end{array}$ & $\begin{array}{c}\text { Jarak } \\
(\mathbf{c m})\end{array}$ & $\begin{array}{c}\text { Sudut } \\
\text { Pandang } \\
(\mathbf{(})\end{array}$ & $\begin{array}{c}\text { Ketinggi } \\
\text { an }(\mathbf{c m})\end{array}$ \\
\hline 5 & $0-10$ & 5 & 5,3 & $3-13$ & 6 \\
15 & $10-20$ & 8 & 15,6 & $12-23$ & 9 \\
25 & $20-30$ & 10 & 25,4 & $24-32$ & 11
\end{tabular}

\begin{tabular}{|c|c|c|c|c|c|}
\hline \multicolumn{6}{|c|}{ PERCOBAAN 2} \\
\hline \multicolumn{3}{|c|}{ Objek } & \multicolumn{3}{|c|}{ Radar } \\
\hline $\begin{array}{l}\text { Jarak } \\
\text { (cm) }\end{array}$ & $\begin{array}{c}\text { Sudut } \\
\text { Pandang } \\
\left({ }^{\circ}\right)\end{array}$ & $\begin{array}{l}\text { Ketinggi } \\
\text { an }(\mathbf{c m})\end{array}$ & $\begin{array}{c}\text { Jarak } \\
(\mathrm{cm})\end{array}$ & $\begin{array}{c}\text { Sudut } \\
\text { Pandang } \\
\left({ }^{\circ}\right)\end{array}$ & $\begin{array}{l}\text { Ketinggi } \\
\text { an }(\mathrm{cm})\end{array}$ \\
\hline 5 & $40-50$ & 5 & 5,4 & $41-52$ & 6 \\
\hline 15 & $50-60$ & 8 & 15,4 & $53-64$ & 9 \\
\hline 25 & $60-70$ & 10 & 25,4 & $62-73$ & 12 \\
\hline
\end{tabular}

\begin{tabular}{ccc|ccc}
\hline \multicolumn{5}{c}{ PERCOBAAN 3 } \\
\hline $\begin{array}{c}\text { Jarak } \\
(\mathbf{c m})\end{array}$ & $\begin{array}{c}\text { Objek } \\
\text { Pandut } \\
\left({ }^{\mathbf{(}}\right)\end{array}$ & $\begin{array}{c}\text { Ketinggi } \\
\text { an }(\mathbf{c m})\end{array}$ & $\begin{array}{c}\text { Jarak } \\
(\mathbf{c m})\end{array}$ & $\begin{array}{c}\text { Sudut } \\
\text { Pandang } \\
\left(\mathbf{(}^{\circ}\right)\end{array}$ & $\begin{array}{c}\text { Ketinggi } \\
\text { an }(\mathbf{c m})\end{array}$ \\
\hline 5 & $80-90$ & 5 & 5,3 & $82-95$ & 6 \\
15 & $90-$ & 8 & 15,5 & $92-125$ & 9 \\
25 & $\begin{array}{c}120 \\
100-\end{array}$ & 10 & 25,6 & $\begin{array}{c}102- \\
165\end{array}$ & 12
\end{tabular}

\section{KESIMPULAN}

Dari hasil pengujian dan analisa yang telah dilakukan pada alat protipe radar untuk pengukuran jarak, sudut dan ketinggian objek dengan python, dapat diambil beberapa kesimpulan sebagai berikut :

1. Radar ultrasonik dapat menentukan jarak, sudut dan ketinggian objek dengan tingkat kesalahan. Sebesar $1-2$ $\mathrm{cm}$ sedangkan untuk sudut pandang 250.

2. Kecepatan pergerakan servo mempengaruhi pada kepresisian pengukuran.

\section{DAFTAR PUSTAKA}

A. M. Kamal, S. H. Hemel and M. U. Ahmad, "Comparison of Linear Displacement Measurements Between A Mems Accelerometer and Hc-Sr04 Low-Cost Ultrasonic Sensor," 2019 1st International Conference on Advances in Science,
Engineering and Robotics Technology (ICASERT), 2019, pp. 1-6, doi: 10.1109/ICASERT.2019.8934569.

Gabriel, M. M., \& Kuria, K. P. (2020). Arduino Uno, Ultrasonic Sensor HC-SR04 Motion Detector with Display of Distance in the LCD. International Journal of Engineering Research and Technical Research, 9.

Gandha, G. I., \& Nurcipto, D. (2019). The Performance Improvement of the Low-Cost Ultrasonic Range Finder (HC-SR04) Using Newton's Polynomial Interpolation Algorithm. JURNAL INFOTEL, 11(4), 108-113.

Morgan, E. J. (2014). HC-SR04 ultrasonic sensor.

Mahboob, T. Z. (2016). Adopting Information Security Techniques for Cloud ComputingA Survey. International Conference on Information Technology, (pp. pp 7 - 11). Yogyakarta: Information Systems and Electrical Engineering (ICITISEE).

Perkasa, T. R., Widyantara, H., \& Susanto, P. (2021). RANCANG BANGUN PENDETEKSI GERAK MENGGUNAKAN METODE IMAGE SUBTRACTION PADA SINGLE BOARD COMPUTER (SBC). Journal of Control and Network Systems , 3 (2), 90-97.

Pramagusta, A. P., Putra, M., Santoso, B., \& Ridho, M. S. (2019). Rancang Bangun Sistem Sensor True Wind untuk Automatic Weather Station di Kapal. Senter : Seminar Nasional Teknik Elektro , 121-134.

Pramana, R., \& Nababan, R. (2019). Perancangan Perangkat Penghitung Jumlah Penumpang Pada Kapal Komersial menggunakan Mikrokontroller. Jurnal Sustainable : Jurnal Hasil Terapan dan Industri Terapan , 8 (1), 18 - 29.

Radar. (2018). Retrieved Juni 2021, from Wikipedia: https://id.wikipedia.org/wiki/Radar

Renaldi, L., Hadiyoso, S., \& Ramadan, D. N. (2017). PROTOTIPE RADAR SEBAGAI PENDETEKSI OBJEK. E-Proceeding of Applied Science, 3, pp. 2159-2165. 
Renaldi, L., Hadiyoso, S., \& Ramadan, D. N. (2018). Purwarupa Radar sebagai Pendeteksi Benda Diam Menggunakan Ultrasonik. ELKOMIKA , 6 (3), 317-327.

Sukmawati, N., Sawitri, A., \& G.N, M. R. (2020). Rancang Bangun Seleksi Kendaraan Sederhana Menggunakan Sensor HC-SR04. SAINTIFIK (Jurnal Matematika, Sains, dan Pembelajarannya) , 6 (1), 49-65.

Sukmawati, N., Sawitri, A., \& G.N, M. (2020). Rancang Bangun Seleksi Kendaraan Sederhana Menggunakan Sensor HC-SR04. Jurnal Matematika, Sains, dan Pembelajarannya , 6 (1), 49-56.

Waliulu, R. (2018). Deteksi dan Penggolongan Kendaraan dengan Kalman Filter dan Model Gaussian di Jalan Tol. JSINBIS (Jurnal Sistem Informasi Bisnis), 8(1), 18. 